\title{
Fish-Mouth Papilla with Mucin Hypersecretion
}

National Cancer Institute

\section{Source}

National Cancer Institute. Fish-Mouth Papilla with Mucin Hypersecretion. NCI Thesaurus.

Code C113103.

An endoscopic finding indicating the presence of a wide-opened papilla filled with mucin. 